\title{
Photochemistry of 5-allyloxy-tetrazoles: steady-state and laser flash photolysis study $\uparrow$
}

\author{
L. M. T. Frija, ${ }^{a, b}$ I. V. Khmelinskii, ${ }^{c}{ }^{\text {C. Serpa }},{ }^{b}$ I. D. Reva, ${ }^{b}$ R. Fausto ${ }^{b}$ and M. L. S. Cristiano ${ }^{* a}$ \\ Received 22nd November 2007, Accepted 24th January 2008 \\ First published as an Advance Article on the web 14th February 2008 \\ DOI: $10.1039 / b 718104 c$
}

The photochemistry of three 5-allyloxy-tetrazoles, in methanol, acetonitrile and cyclohexane was studied by product analysis and laser flash photolysis. The exclusive primary photochemical process identified was molecular nitrogen elimination, with formation of 1,3-oxazines. These compounds were isolated in reasonable yields by column chromatography on silica gel and were fully characterized. DFT(B3LYP)/6-31G(d,p) calculations predict that these 1,3-oxazines can adopt two tautomeric forms (i) with the $\mathrm{NH}$ group acting as a bridge connecting the oxazine and phenyl rings and (ii) with the $-\mathrm{N}=$ bridge and the proton shifted to the oxazine ring. Both tautomeric forms are relevant in the photolysis of oxazines in solution. Secondary reactions were observed, leading to the production of phenyl vinyl-hydrazines, enamines, aniline and phenyl-isocyanate. Transient absorption, detected by laser flash photolysis, is attributed to the formation of triplet 1,3-biradicals generated from the excited 5-allyloxy-tetrazoles. The 1,3-biradicals are converted to 1,6-biradicals by proton transfer, which, after intersystem crossing, decay to generate the products. Solvent effects on the photoproduct distribution and rate of decomposition are negligible.

\section{Introduction}

Tetrazoles have received much attention due to their important industrial and biological practical applications. ${ }^{1}$ Most of these applications are related to the acid-base properties of the tetrazolic ring. In fact, the tetrazolic acid fragment, $-\mathrm{CN}_{4} \mathrm{H}$, has similar acidity to the carboxylic acid group, $-\mathrm{CO}_{2} \mathrm{H}$, and is almost isosteric with it, being metabolically more stable at physiologic $\mathrm{pH} .{ }^{2}$ This metabolic stability of the tetrazole ring strongly influences applications of its derivatives in medicine and, then, this heterocycle comes out in the structure of many highly efficient drugs. ${ }^{3-9}$ Tetrazoles are also used as stabilizers in photography, gas-generating agents in airbags in the automobile industry, and herbicides, fungicides and plant growth regulators in agriculture. ${ }^{10,11}$

In view of the widespread importance of many tetrazolyl derivatives, we have held a continued interest in structure-reactivity relationships of this class of compounds. Recently, photochemical reactions of tetrazole-based compounds have been under scrutiny in our group.

The photochemistry of tetrazole and some substituted tetrazoles has been addressed elsewhere. According to these investigations, tetrazole-ring cleavages leading either to azides or aziridines represent the main characteristic photochemical reactions of this

${ }^{a}$ Department of Chemistry, Biochemistry and Pharmacy, F.C.T. and CCMAR, University of Algarve, 8005-039 Faro,Portugal.E-mail: mcristi@, ualg.pt

${ }^{b}$ Department of Chemistry, F.C.T., University of Coimbra, R. Larga, P3004-535 Coimbra, Portugal

'Department of Chemistry, Biochemistry and Pharmacy, F.C.T and CIQA, University of Algarve, 8005-039 Faro, Portugal

$\dagger$ Electronic supplementary information (ESI) available: ${ }^{1} \mathrm{H}$ NMR for compounds $\mathbf{4 a - c}$, geometries and energies of compounds $\mathbf{4 a - c}, \mathbf{5 a}-\mathbf{c}, \mathbf{6}$, $\mathbf{7 a - c , ~ 8 , 9 , 1 0}$ and $\mathbf{1 1 a}-\mathbf{c}$, and Cartesian coordinates of compounds $\mathbf{4 a - c}$, $\mathbf{5 a}-\mathbf{c}, \mathbf{6}, \mathbf{7 a}-\mathbf{c}, \mathbf{8}, \mathbf{9}, \mathbf{1 0}$ and 11a-c. See DOI: $10.1039 / \mathrm{b} 718104 \mathrm{c}$ family of heterocycles. However, the nature of the ring substituents strongly determines the precise nature and relative amounts of the final photoproducts, making this type of compound an ongoing scientific challenge. ${ }^{12-14}$

In previous contributions we have described the photochemistry of some representative tetrazolyl compounds isolated in lowtemperature matrices. ${ }^{15-20}$ Recently we have also studied the photochemistry of a series of 4-allyl-tetrazolones (1, Scheme 1) in solution, ${ }^{21}$ and proved that photolysis in alcoholic solutions results in exclusive formation of 3,4-dihydro-6-substituted-3phenylpyrimidin-2(1H)-ones $(2$, Scheme 1$)$, which are versatile intermediates in heterocyclic synthesis. ${ }^{22}$

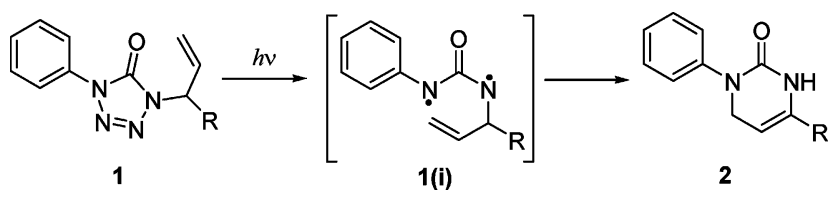

Scheme 1 Photochemical conversion of 4-allyl-tetrazolones 1 into 3,4-dihydro-6-substituted-3-phenylpyrimidin-2(1H)-ones 2.

Mechanistically, we postulated that these reactions presumably take place via formation of a triplet biradical intermediate 1(i). Photoexcitation of 4-allyl-tetrazolones promoted by UV radiation leads to elimination of $\mathrm{N}_{2}$ from the tetrazole ring, yielding the biradical 1(i). In a second step, this intermediate rapidly undergoes a 1,2-migration of hydrogen and closes the ring to form the pyrimidinone $\mathbf{2}$, in an exothermic process.

The participation of the reactive triplet intermediate 1(i) could not be unequivocally proved. However, this mechanism is supported by the effect of solvent viscosity on the photolysis quantum yields, and the sensitizing effect of the dissolved oxygen upon the photodegradation of tetrazolone $\mathbf{1}$, interpreted as a consequence of the $\mathrm{T} \rightarrow \mathrm{S}$ conversion of triplet biradicals 1(i) opening the way 
to the formation of the product 2 . Both effects were explained by the involvement of a caged triplet radical pair. ${ }^{21}$

Dunkin et al. described the photochemistry of 1,4-dihydro$5 \mathrm{H}$-tetrazole derivatives isolated in low-temperature matrices. ${ }^{23}$ In that work, the authors also interpreted the results obtained upon matrix photolysis on the basis of a biradical intermediate, invoking a mechanism similar to the one proposed by us for the photo-conversion of 4-allyl-tetrazolones into pyrimidinones. Earlier, Quast and co-workers had studied the photochemistry of a series of tetrazole derivatives, concluding that the photochemically induced opening of the tetrazole ring is a very common process. ${ }^{24-28}$

Herein we present results on the photochemistry of 5-allyloxytetrazoles (3a-c, Scheme 2) in solution. Besides our own interest in understanding the mechanism of photocleavage of these ethers, the possibility of isolation and characterization of reaction photoproducts may be particularly important for synthetic applications.

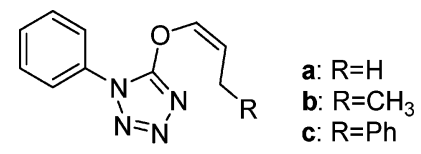

3

Scheme 2 Structure of 5-allyloxy-tetrazoles 3a-c.

\section{Results and discussion}

\section{Steady-state photolysis: photoreactivity and photoproduct distribution}

The 5-allyloxy-tetrazoles studied were synthesized from the corresponding allylic alcohols, initially converted into the alkoxides with sodium hydride, and then reacted with 5-chloro-1phenyltetrazole. $^{29}$

UV spectra of ethers $\mathbf{3} \mathbf{a}$ and $\mathbf{3 b}$ show absorption maxima around $230 \mathrm{~nm}$, while the ether $\mathbf{3 c}$ exhibits an intense absorption band at about $250 \mathrm{~nm}$, due to the bathochromic effect of the phenyl ring (Fig. 1). The substrates dissolved in methanol, acetonitrile and cyclohexane were irradiated with a low-pressure mercury lamp $(\lambda=254 \mathrm{~nm})$. The progress of the photoreactions was monitored by HPLC and GC-MS and the quantum yields for photocleavage were determined in each one of the tested solvents.

Fig. 1 shows changes in the UV absorption spectra of compounds $3 \mathbf{a}-\mathbf{c}$ caused by the irradiation $(\lambda=254 \mathrm{~nm})$ of their airequilibrated methanolic solutions. For compound 3a, the absorption peak around $230 \mathrm{~nm}$ decreased with irradiation time, while a new absorption band grew at $238 \mathrm{~nm}$. These spectral changes are very similar to those observed for derivative $\mathbf{3 b}$, indicating that the methyl group attached to the allylic chain exerts a negligible effect on the photoreactivity. Moreover, in the spectra of compounds 3a and 3b (Fig. 1), the absorptivity at $254 \mathrm{~nm}$ registered for the new band belonging to the photoproducts is higher than that of the initial substrates at the same wavelength. This fact will significantly reduce the apparent photodecomposition rates of the two ethers, since the formed photoproducts absorb a large part of the incident UV light.

Interestingly, for ether $\mathbf{3 c}$, the reaction proceeds faster than for compounds $\mathbf{3 a}$ and $\mathbf{3 b}$, as seen from their absorption spectral changes, showing an isosbestic point at $\approx 275 \mathrm{~nm}$. In Fig. 1 (3c)
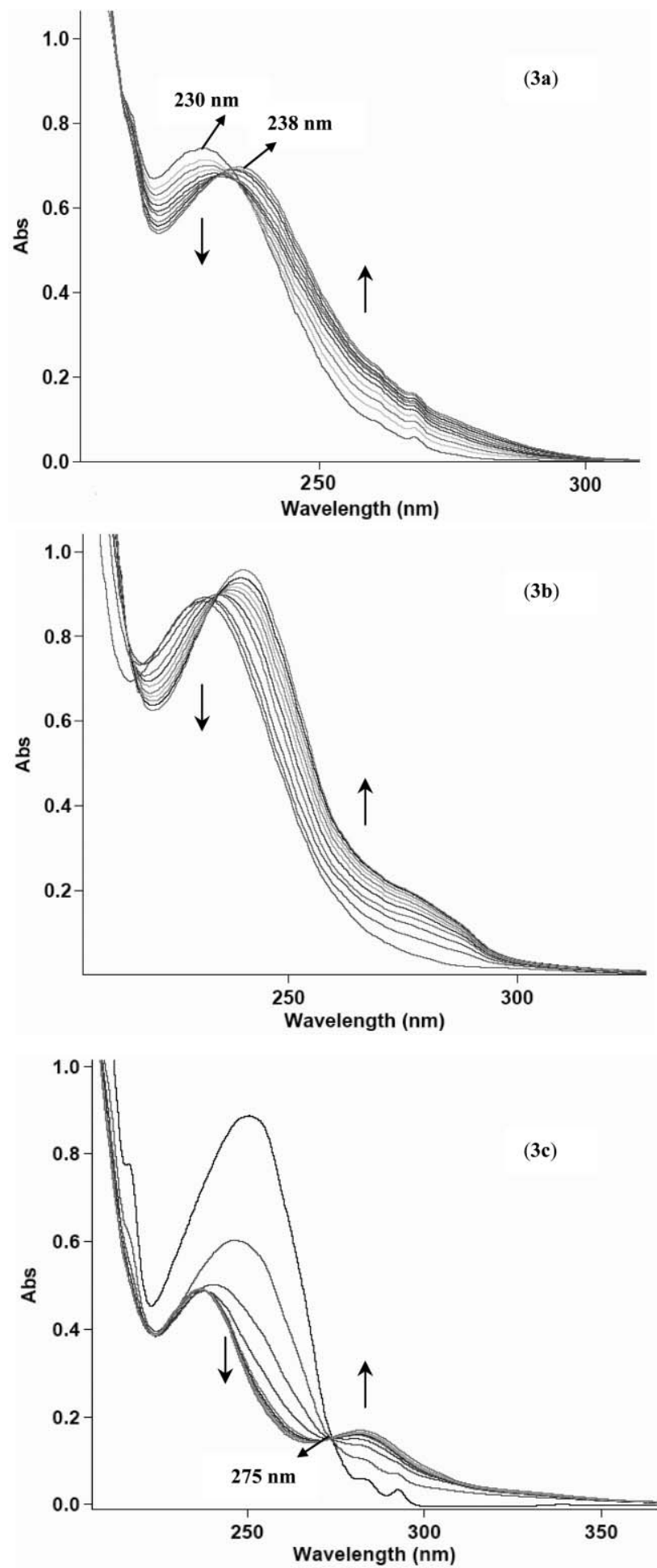

Fig. 1 Changes in UV spectra of 5-allyloxy-tetrazoles 3a-c in methanol $\left(1 \times 10^{-4} \mathrm{~mol} \mathrm{dm}^{-3}\right)$ induced by UV irradiation $(\lambda=254 \mathrm{~nm})$ at room temperature, with intervals of $30 \mathrm{~s}(\mathbf{3 a}, \mathbf{3 b})$ and $15 \mathrm{~s}(\mathbf{3} \mathbf{c})$. The vertical arrows indicate the evolution of absorbance with the irradiation time.

we can observe that the absorptivity at $254 \mathrm{~nm}$ registered for the new bands belonging to the photoproducts is lower than that of the initial substrate at the same wavelength. For derivative $\mathbf{3 c}$, the competition for the UV light between the photoproducts and the 
substrate is much less marked, due to the absorption of the large part of the incident UV light by the substrate.

HPLC and GC-MS analysis of irradiated methanolic solutions of ethers $\mathbf{3 a - c}$ led to the identification of one primary photoproduct for each of the three derivatives. These primary photoproducts result from $\mathrm{N}_{2}$ elimination from the tetrazolyl ring system through photo-induced cleavage of the two weakest $\mathrm{N}-\mathrm{N}$ formally single bonds of the heterocycle, and were characterized as $N$-phenyl-1,3oxazines $4 \mathbf{a}(m / z=174), \mathbf{4 b}(m / z=188)$ and $\mathbf{4 c}(m / z=251)$ (see Fig. 2). Preparative-scale irradiations of the three tetrazolyl ethers in methanol were performed, aiming at the isolation of the primary photoproducts. These irradiations were carried out in cylindrical quartz cells with a $50 \mathrm{~mm}$ light path, using $50 \mathrm{mg}$ of the starting material (see experimental section) and were controlled by TLC and HPLC. Irradiation of the sample continued until the first detection of a secondary photoproduct. The remaining starting material was separated from the primary photoproduct by column chromatography on silica gel. Mass spectrometry (CI)

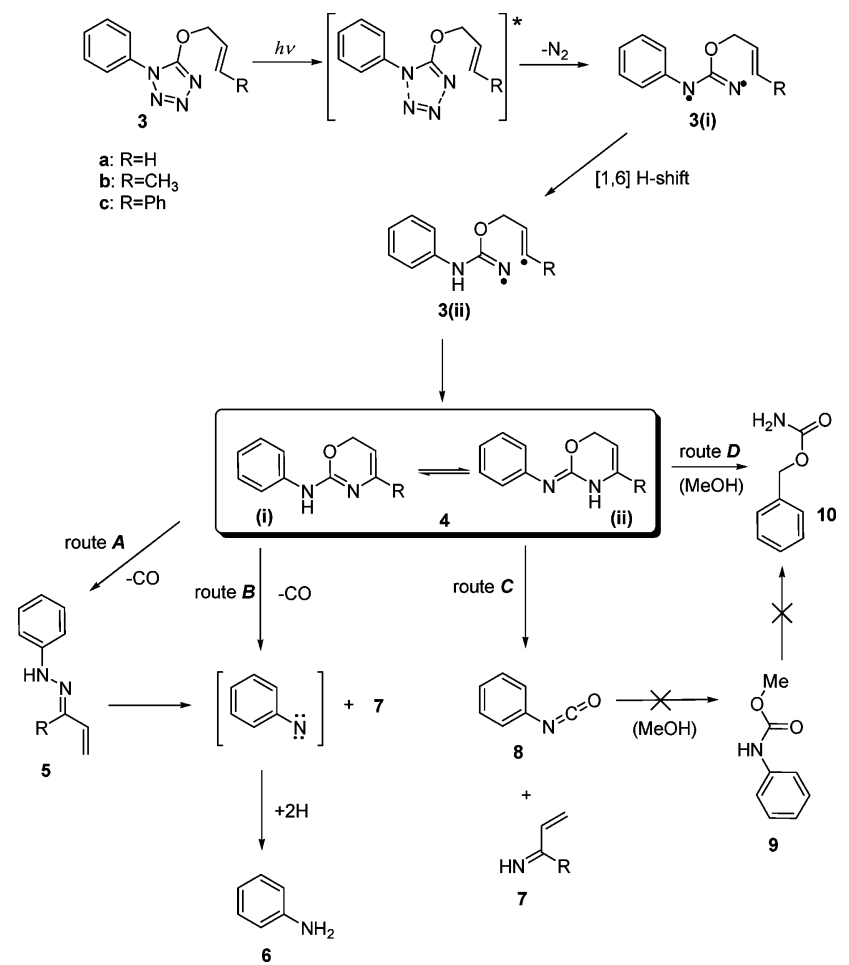

Fig. 2 Proposed photodegradation pathways for 5-allyloxy-tetrazoles 3a-c, in solution. and ${ }^{1} \mathrm{H}-\mathrm{NMR}$ analysis of the isolated primary extracts confirmed the structures of compounds $\mathbf{4 a}-\mathbf{c}$.

Oxazines $\mathbf{4 a - c}$ can adopt two tautomeric forms, depending on the position of the amino function on the molecule. The $\mathrm{NH}$ group can act as a bridge, connecting the oxazine and phenyl rings, or this group can be alternatively included in the oxazine ring. DFT calculations performed at the $\mathrm{B} 3 \mathrm{LYP} / 6-31 \mathrm{G}(\mathrm{d}, \mathrm{p})$ level of theory carried out for the two tautomers of oxazines $\mathbf{4 a}$ and $\mathbf{4 b}$, led to the identification, for both compounds, of two low-energy local minima when the $\mathrm{NH}$ group is connected to the two rings (structure 4(i) in Fig. 2), and of three lowenergy local minima when the $\mathrm{NH}$ function is included in the oxazine ring (structure 4(ii) in Fig. 2). Calculations performed at the same level of theory for oxazine $\mathbf{4 c}$ revealed nine lowenergy local minima for the two tautomers of this compound: four minima with the $\mathrm{NH}$ group linking the phenyl and oxazine rings, and five minima with the $\mathrm{NH}$ included on the oxazine ring. All possible conformers and tautomers of oxazines $\mathbf{4 a - c}$ have been theoretically investigated and the calculated Hessian matrices showed no imaginary frequencies, confirming that all the structures are true energy minima. For simplicity, only the data for the most stable structure of each compound are included in the ESI (pages S4-S6). $\dagger$

In order to estimate the conformational and tautomeric composition of compounds $\mathbf{4 a - c}$ in solution, the thermochemical calculations were carried out for all compounds at $25{ }^{\circ} \mathrm{C}$. Based on the calculated Gibbs free energies, the equilibrium Boltzmann populations were estimated for all tautomers/conformers and the selected results are presented in Table 1.

Because of the significant energy differences between the tautomers 4(i) and 4(ii), it can be expected that the population of oxazines at $25^{\circ} \mathrm{C}$ will be dominated by structures 4 (i). Indeed, for all compounds $\mathbf{4 a - c}$, predicted populations of forms $\mathbf{4}$ (i) exceed $96 \%$ (see Table 1). The contribution of the minor tautomer 4(ii) to the equilibrium mixture was predicted to range from about 2 to $4 \%$, for isolated molecules in vacuum. It is important to call attention to the fact that the total dipole moments of tautomers 4(ii) are systematically higher than those of the tautomers 4(i) (Table 1). It may be expected that, in the polar media, forms 4(ii) will undergo additional stabilization with respect to forms 4 (i), and the relative population of the minor conformer will increase. Based on this reasoning, we may conclude that both the tautomers 4(i) and 4(ii) will be relevant for further photolysis of oxazines $4 a-c$ in solution. Therefore, the secondary photoproducts of 5-allyloxytetrazoles 3a-c will be formed via photodecomposition of forms 4(i) and 4(ii), as presented in Fig. 2.

Table 1 B3LYP/6-31G(d,p) calculated relative energies, populations and dipole moments for tautomers (i) and (ii) of oxazines $4 \mathbf{a}-\mathbf{c}^{a}$

\begin{tabular}{|c|c|c|c|c|c|c|}
\hline Substrate & \multicolumn{2}{|c|}{ Relative energy $/ \mathrm{kJ} \mathrm{mol}^{-1}$} & \multicolumn{2}{|c|}{ Population (\%) } & \multicolumn{2}{|c|}{ Dipole moment (Debye) } \\
\hline $4 \mathbf{a}$ & 0 & 9.8 & 98.2 & 1.8 & 1.97 & 3.80 \\
\hline $4 b$ & 0 & 7.6 & 96.0 & 4.0 & 1.63 & 4.21 \\
\hline $4 c$ & 0 & 8.2 & 98.3 & 1.7 & 1.88 & 4.33 \\
\hline
\end{tabular}

${ }^{a}$ Relative energies and dipole moments correspond to the most stable conformations of tautomers (i) and (ii); populations correspond to the sum of populations of all conformers within a given tautomer, and were estimated based on the calculated relative Gibbs energies at $25^{\circ} \mathrm{C}$. 
We propose four different photochemical channels for the photodegradation of oxazines $\mathbf{4 a}-\mathbf{c}$ in methanol (routes $\boldsymbol{A}-\boldsymbol{D}$, Fig. 2).

In the first channel (route $\boldsymbol{A}$ ), photoproduct 5 (a phenyl vinylhydrazine) is formed by extrusion of carbon monoxide from the oxazine ring. In the second photochemical channel (route $\boldsymbol{B}$ ), the oxazine is directly converted, via a concerted mechanism, into aniline $\mathbf{6}$ and photoproduct 7 , also with $\mathrm{CO}$ extrusion.

The proposal of the independent photochemical channel (route A) leading to formation of aniline and products 5 and 7, is fully justified by the fact that product $\mathbf{5}$ and aniline start to be detected at the same reaction time. Upon continued exposure to UV radiation, even after complete decomposition of substrates 3a-c into the primary photoproducts, we noted that the concentration of product $\mathbf{5}$ was decreasing, accompanied by a similar growth of aniline concentration. Hence, aniline and product 7 cannot result exclusively from oxazine photodecomposition through a concerted mechanism (route B), being also a product of photodecomposition of the photoproduct 5 (route $\boldsymbol{A}$ ). Probably, both routes $\boldsymbol{A}$ and $\boldsymbol{B}$ operate via the same transient species formed after absorption of a photon by the oxazine tautomers 4(i) (Fig. 2).

The production of aniline, directly from oxazine tautomers 4(i) or by photodegradation of compound $\mathbf{5}$, should involve the formation of the phenylnitrene intermediate [Ph-N:], which subsequently abstracts two hydrogen atoms from the environment, forming product 6 (see Fig. 2). The proposed source of the two hydrogen atoms required to form aniline will be addressed further in this work, together with a discussion of the kinetics of the photoreactions.

The photoproducts $7 \mathbf{a}(\mathrm{R}=\mathrm{H} ; m / z=55)$ and $7 \mathbf{b}\left(\mathrm{R}=\mathrm{CH}_{3}\right.$; $m / z=69$ ) have never been detected chromatographically in the course of the irradiation experiments. This could be explained by their high volatility, fast photodecomposition into molecular products of lower weight, or very rapid elution in the chromatographic conditions used. On the other hand, the photoproduct 7c $(\mathrm{R}=\mathrm{Ph} ; m / z=131)$ was clearly identified by GC-MS. The attribution of chemical structures to products 5 and 7 was based on their mass spectra, through the analysis of the fragmentation patterns exhibited. Aniline was easily identified, comparing the respective chromatogram with that of an authentic aniline sample.

A single photochemical channel is proposed for the formation of product $\mathbf{8}$ (phenyl-isocyanate). This species is formed via degradation of the minor oxazine tautomer 4(ii) (route $\boldsymbol{C}$, Fig. 2). As for aniline, phenyl-isocyanate was identified using an authentic sample for comparison. Formation of phenyl-isocyanate in the photochemical channel $\boldsymbol{C}$ implies formation of a by-product also produced in routes $\boldsymbol{A}$ and $\boldsymbol{B}$, namely product $\mathbf{7}$.

Apparently, phenyl-isocyanate, also obtained as a stable secondary photoproduct upon photolysis of 4-allyl-tetrazolones ${ }^{21}$ could undergo photocleavage to phenylnitrene [Ph-N:], with elimination of $\mathrm{CO}$, which could then abstract hydrogen to form aniline. However, in view of the experimental observations, we consider that aniline and phenyl-isocyanate are produced via two independent photodegradation channels of oxazines (routes $\boldsymbol{A}$, $\boldsymbol{B}$ and $\boldsymbol{C}$, Fig. 2). In the course of the irradiation experiments, simultaneous formation of photoproducts $\mathbf{6}$ and $\mathbf{8}$ was detected, indicating that aniline does not derive from phenyl-isocyanate. This hypothesis was confirmed by HPLC analysis of irradiated solutions of phenyl-isocyanate in methanol, under conditions similar to those used for 5-allyloxy-tetrazoles 3a-c. Phenylisocyanate remained photostable upon prolonged irradiation at $254 \mathrm{~nm}$, and no aniline formation was ever detected.

Another photoproduct was identified upon irradiation of ethers 3a-c in methanolic solutions, namely benzyl carbamate $(\mathbf{1 0}, \mathrm{m} / \mathrm{z}=$ 151) (route $\boldsymbol{D}$, Fig. 2). One possible explanation for the formation of compound $\mathbf{1 0}$ could be the rearrangement of methyl phenylurethane (9, Fig. 2), produced from the reaction of phenylisocyanate, formed via route $\mathbf{C}$, with a solvent molecule. To check this hypothesis, we have used an authentic sample of carbamate $\mathbf{9}$ and irradiated it in a methanolic solution under conditions similar to those used for the tetrazolyl ethers. However, chromatographic analysis demonstrated that benzyl carbamate is not a product of photodegradation of carbamate $\mathbf{9}$. Therefore, at the present stage the pathway leading to formation of benzyl carbamate $\mathbf{1 0}$ upon photolysis of tetrazolyl ethers $\mathbf{3 a}-\mathbf{c}$ remains unclear.

The kinetics of photodecomposition of 5-allyloxy-tetrazoles 3a-c in methanolic solution are shown in Fig. 3, along with the kinetics of photoproducts formation. After 120 minutes of UV-irradiation, about $90 \%$ of the reagents $\mathbf{3 a}-\mathbf{c}$ were consumed. The photodecomposition of ether $\mathbf{3 c}$ occurs faster. After 30 minutes, $63 \%$ of compound $3 \mathbf{c}$ was consumed, against $38 \%$ for compounds $\mathbf{3 a}, \mathbf{b}$. After formation of the primary photoproducts $\mathbf{4 a - c}$, we found that, among the secondary photoproducts, the transformation of oxazines into phenyl-isocyanate (route $\boldsymbol{C}$, Fig. 2) proceeds with the highest efficiency, as can be observed in Fig. 3. This observation indicates that, in solution, the population of tautomer with the higher dipole moment, 4(ii), might be higher than that predicted for the gas phase on the basis of molecular orbital calculations. But more important is the fact that the population of 4(ii) is constantly maintained as "small-but-present" due to dynamic equilibrium with $\mathbf{4 ( i )}$ in solution. Then the photoreaction may be derived from the constantly re-populated 4(ii), if 4(i) is not reactive (or not reactive enough) and serves mainly as a source of $\mathbf{4}$ (ii).

Fig. 4 shows the changes in the UV absorption spectra of ethers 3a-c upon UV-irradiation $(\lambda=254 \mathrm{~nm})$ in air-equilibrated acetonitrile and cyclohexane solutions. The evolution of the UV absorption spectra reveals that the photoreactivity of $\mathbf{3 a}-\mathbf{c}$ should be very similar in acetonitrile and cyclohexane. The absorption band around $230 \mathrm{~nm}$ present in the spectra of compounds 3a and $\mathbf{3 b}$ decreased with irradiation time, while a new band grew at $238 \mathrm{~nm}$. Fig. 5 shows the kinetics for the photodecomposition of 5-allyloxy-tetrazoles (3a-c) in acetonitrile. As in methanol solutions, the photoreactivities of compounds $\mathbf{3} \mathbf{a}$ and $\mathbf{3 b}$ are very similar, whereas the photodecomposition of $\mathbf{3} \mathbf{c}$ is faster. Both the reaction rates and the photoproduct distributions are very similar in the three solvents, with the extrusion of the $\mathrm{N}_{2}$ from the tetrazole ring remaining the sole primary process of photodegradation of tetrazoles $\mathbf{3 a}-\mathbf{c}$, leading to the formation of oxazines $\mathbf{4 a - c}$.

Analysis of the kinetic results obtained for the photodegradation of ethers $\mathbf{3 a}-\mathbf{c}$ in the three tested solvents clearly shows that the effect of the nature of the solvent on the photoproduct distribution is very weak, i.e., the relative percentage of photoproducts is maintained for all cases. In methanolic solution, formation of benzyl-carbamate is observed, due to nucleophilic attack by methanol.

The analysis of the kinetics of photoreactions led us to propose a possible mechanism for aniline formation from phenyl-nitrene 

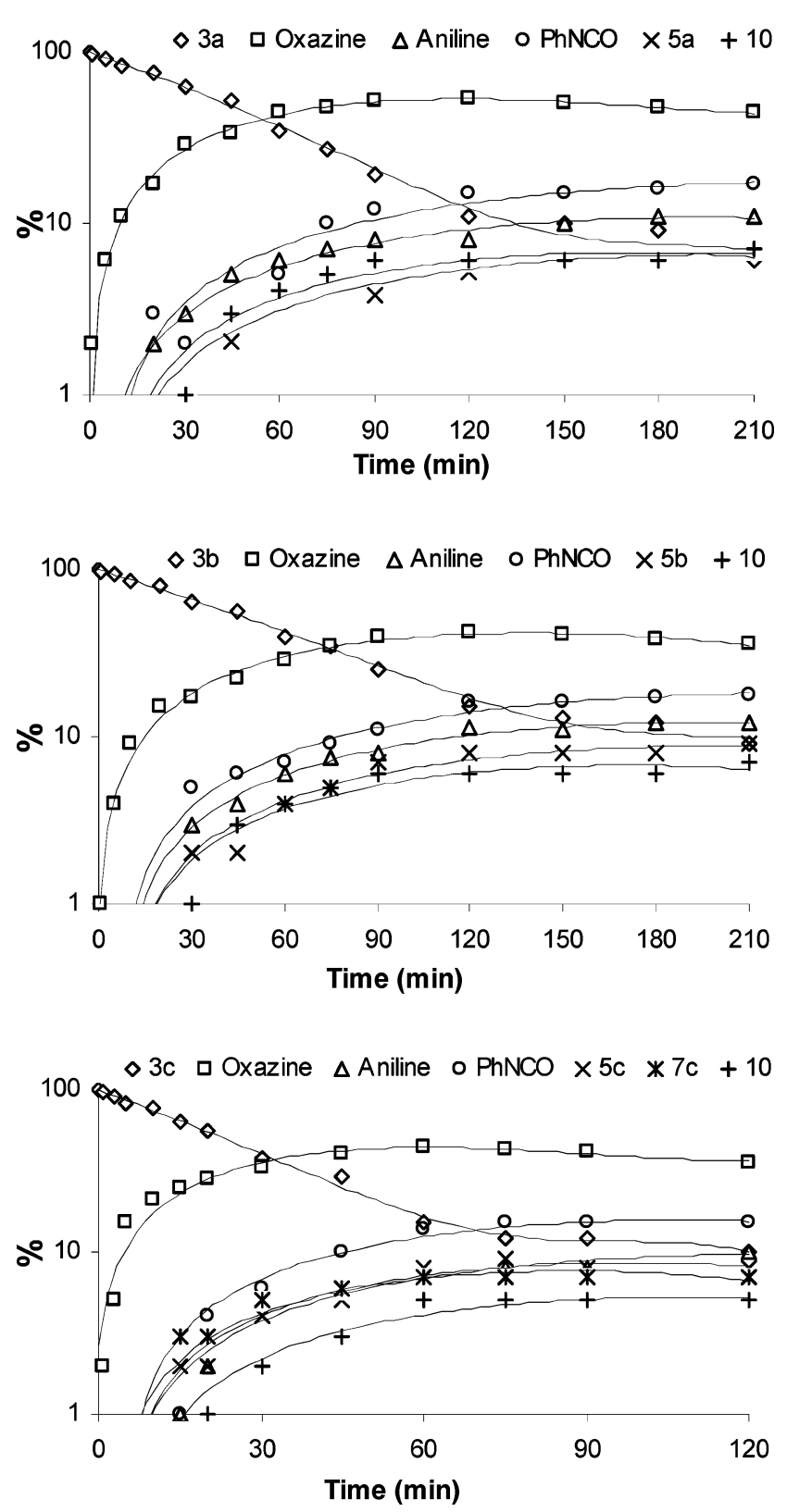

Fig. 3 Time evolution of the amount of 5-allyloxy-tetrazoles 3a-c and of photoproducts resulting from UV-irradiation $(\lambda=254 \mathrm{~nm})$ in methanolic solution $\left(1 \times 10^{-4} \mathrm{~mol} \mathrm{dm}^{-3}\right)$. The amount of reagent before irradiation was assumed to be $100 \%$. The yields of different photoproducts were monitored by gaseous chromatography. Note that the ordinate scale is logarithmic. Note the assignment of geometrical symbols (rhombs-3a-c, squares - oxazine, triangles - aniline, circles - phenylisocyanate, etc.) to particular photoproducts on top of each frame.

in photochannels $\mathbf{A}$ and B. All kinetics resemble each other very closely, and occur in solvents that are very different from the viewpoint of proton-affinities: methanol, cyclohexane and acetonitrile. It is very unlikely that the two additional hydrogen atoms required for formation of aniline are provided by the solvent. Most probably, the compound itself undergoes an additional photochemical transformation resulting in abstraction of two $\mathrm{H}$ atoms. This abstraction does not involve the three R-substituents (hydrogen, methyl, phenyl), since aniline formation is observed in all cases. We suggest that the two hydrogen atoms (the most labile H's) are abstracted from positions 3 and 6 of the oxazine ring of $\mathbf{4 a - c}$ photoproducts in their $\mathbf{4}$ (ii) tautomeric form. The suggested mechanism for hydrogen abstraction is shown in Scheme 3. The optimized structures of derivatives 11a-c are included as ESI (pages S14-S15). $\dagger$ An analogous photochemically induced hydrogen abstraction was reported for 1,4-cyclohexadiene in pentane solution ${ }^{30}$ and the possibility of the occurrence of such a reaction was also shown theoretically. ${ }^{31}$

\section{Photolysis quantum yields}

Quantum yields for the photodecomposition of 5-allyloxytetrazoles 3a-c were determined in the three solvents. They are collected in Table 2 and show that the photoreactivity is very similar in acetonitrile and cyclohexane and is only slightly higher in methanol. Thus, the solvent effect on reactivity is indeed very weak. However, the enhancement of the photolysis quantum yield caused by the introduction of a phenyl on the allylic chain is much more pronounced.

\section{Laser flash photolysis and mechanistic considerations}

Laser flash photolysis of 5-allyloxy-tetrazoles $\mathbf{3 a - c}$ in acetonitrile at $266 \mathrm{~nm}$ revealed formation of short-lived transient species, as detailed in Table 3. The transient decay for ether $\mathbf{3 a}$ is apparently biexponential, with the contribution of the slower transient increasing at higher concentrations of the substrate. The faster transient for ether $\mathbf{3} \mathbf{a}$ is spectrally similar to that of ether $\mathbf{3 b}$, presented in Fig. 6 (top), with the lifetimes only slightly affected by the presence of dissolved oxygen. We identify these two transients as reactive radical species.

Laser flash photolysis of a deaerated $10^{-4} \mathrm{~mol} \mathrm{dm}^{-3}$ solution of tetrazole $\mathbf{3 b}$ in acetonitrile yielded a wide transient absorption, with a maximum at $300 \mathrm{~nm}$ (see Fig. 6). The lifetime of this species was around $800 \mathrm{~ns}$ under our experimental conditions.

Ether 3c is once again a special case. The corresponding transient appears at shorter wavelengths, with the decay kinetics clearly accelerated by the dissolved oxygen (see Table 3). We identify this transient as a triplet excited state. Compared with

Table 2 Quantum yields ( $\Phi_{\text {obs }}$ ) for the photodegradation of 5-allyloxytetrazoles $3 \mathbf{a}-\mathbf{c}$, in the range of solvents used $\left(\lambda=254 \mathrm{~nm}, 25^{\circ} \mathrm{C}\right)$

\begin{tabular}{llll}
\hline Solvent (air-equilibrated) & 3a, $\Phi_{\text {obs }}$ & 3b, $\Phi_{\text {obs }}$ & 3c, $\Phi_{\text {obs }}$ \\
\hline $\mathrm{CH}_{3} \mathrm{CN}$ & 0.023 & 0.021 & 0.106 \\
$\mathrm{Cyclohexane}_{\mathrm{CH}_{3} \mathrm{OH}}$ & 0.025 & 0.020 & 0.112 \\
& 0.037 & 0.035 & 0.144 \\
\hline
\end{tabular}

Table 3 Selected spectral and kinetic parameters for the transient species detected by laser flash-photolysis ${ }^{a}$

\begin{tabular}{|c|c|c|c|c|}
\hline \multirow[b]{2}{*}{ Ether } & \multicolumn{2}{|l|}{ Transient 1} & \multicolumn{2}{|l|}{ Transient 2} \\
\hline & Lifetime $/ \mu \mathrm{s}$ & $\lambda_{\max } / n m$ & Lifetime $/ \mu \mathrm{s}$ & $\lambda_{\max } / n m$ \\
\hline 3a $\left(\mathrm{N}_{2}\right.$, sat.) & 2.2 & 350 & 13.8 & 310 \\
\hline 3a $\left(\mathrm{O}_{2}\right.$, sat.) & 1.3 & 330 & 10.0 & 290 \\
\hline $3 \mathbf{b}\left(\mathrm{N}_{2}\right.$, sat.) & 0.8 & 300 & - & - \\
\hline $3 \mathbf{b}\left(\mathrm{O}_{2}\right.$, sat.) & 0.7 & 320 & - & - \\
\hline $3 \mathbf{c}\left(\mathrm{N}_{2}\right.$, sat.) & 2.3 & 290 & - & - \\
\hline $3 \mathbf{c}\left(\mathrm{O}_{2}\right.$, sat. $)$ & 0.5 & 290 & - & - \\
\hline
\end{tabular}

${ }^{a}$ Results obtained in acetonitrile with excitation at $266 \mathrm{~nm}$. 

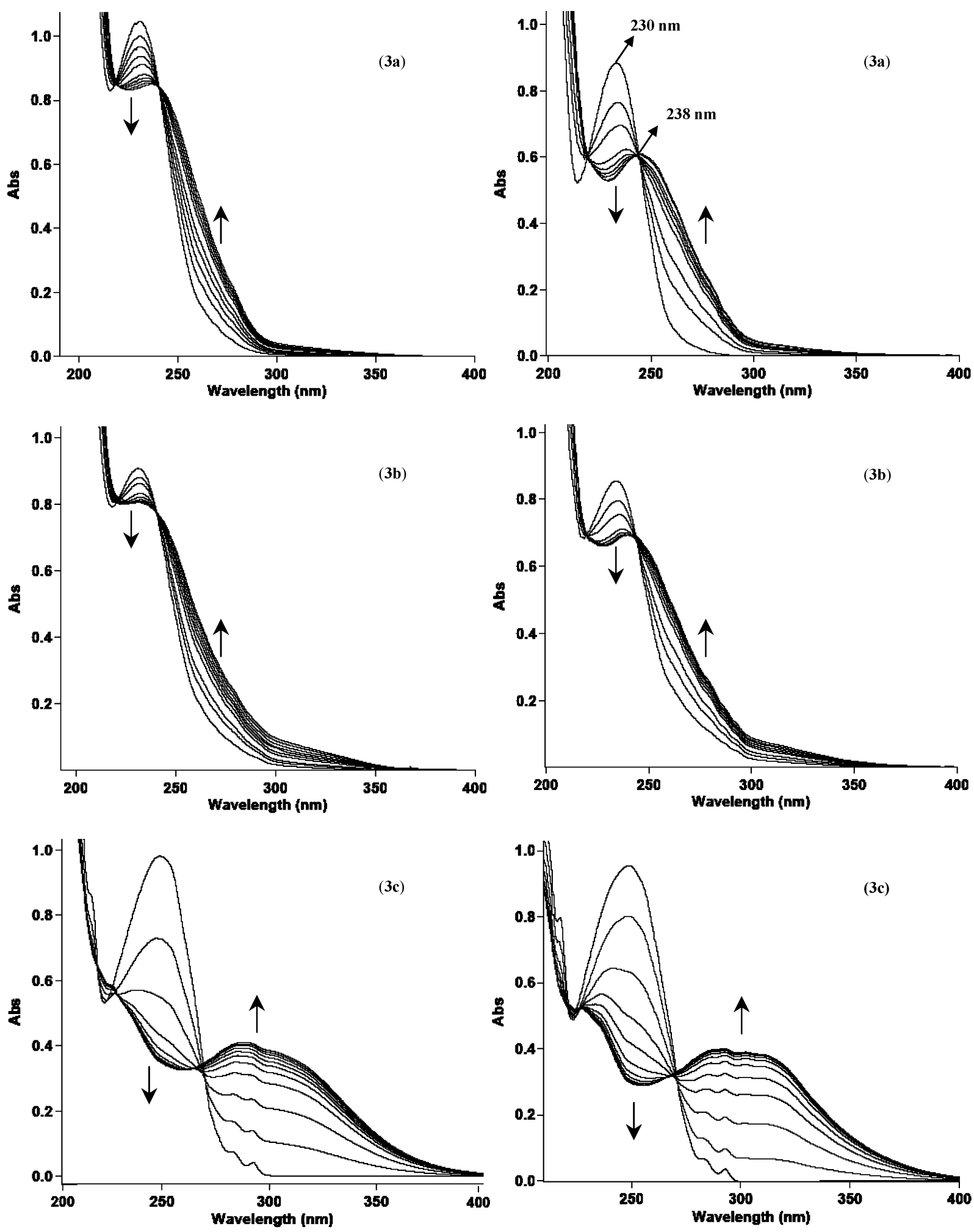

Fig. 4 Changes in UV spectra of 5-allyloxy-tetrazoles 3a-c in acetonitrile (left $)$ and cyclohexane $($ right $)\left(1 \times 10^{-4} \mathrm{~mol} \mathrm{dm}^{-3}\right)$ induced by UV irradiation $(\lambda=254 \mathrm{~nm})$ at room temperature, with intervals of $30 \mathrm{~s}(\mathbf{3 a}, \mathbf{3 b})$ and $15 \mathrm{~s}(\mathbf{3 c})$. The vertical arrows indicate the evolution of absorbance with the irradiation time.

ethers $\mathbf{3 a}-\mathbf{b}$, the excited-state lifetime of the substrate $\mathbf{3 c}$ is increased due to the presence of a larger " $\pi$ "-electronic system, whereas the hydrogen transfer reaction is further accelerated by the presence of the $\mathrm{R}=\mathrm{Ph}$ substituent and does not limit the overall reaction kinetics any more. This justifies the identification of the transients observed for $\mathbf{3} \mathbf{a}-\mathbf{b}$ as radical species, and that for $\mathbf{3 c}$ as the triplet excited state. This assumption is further supported by the considerations that follow. 

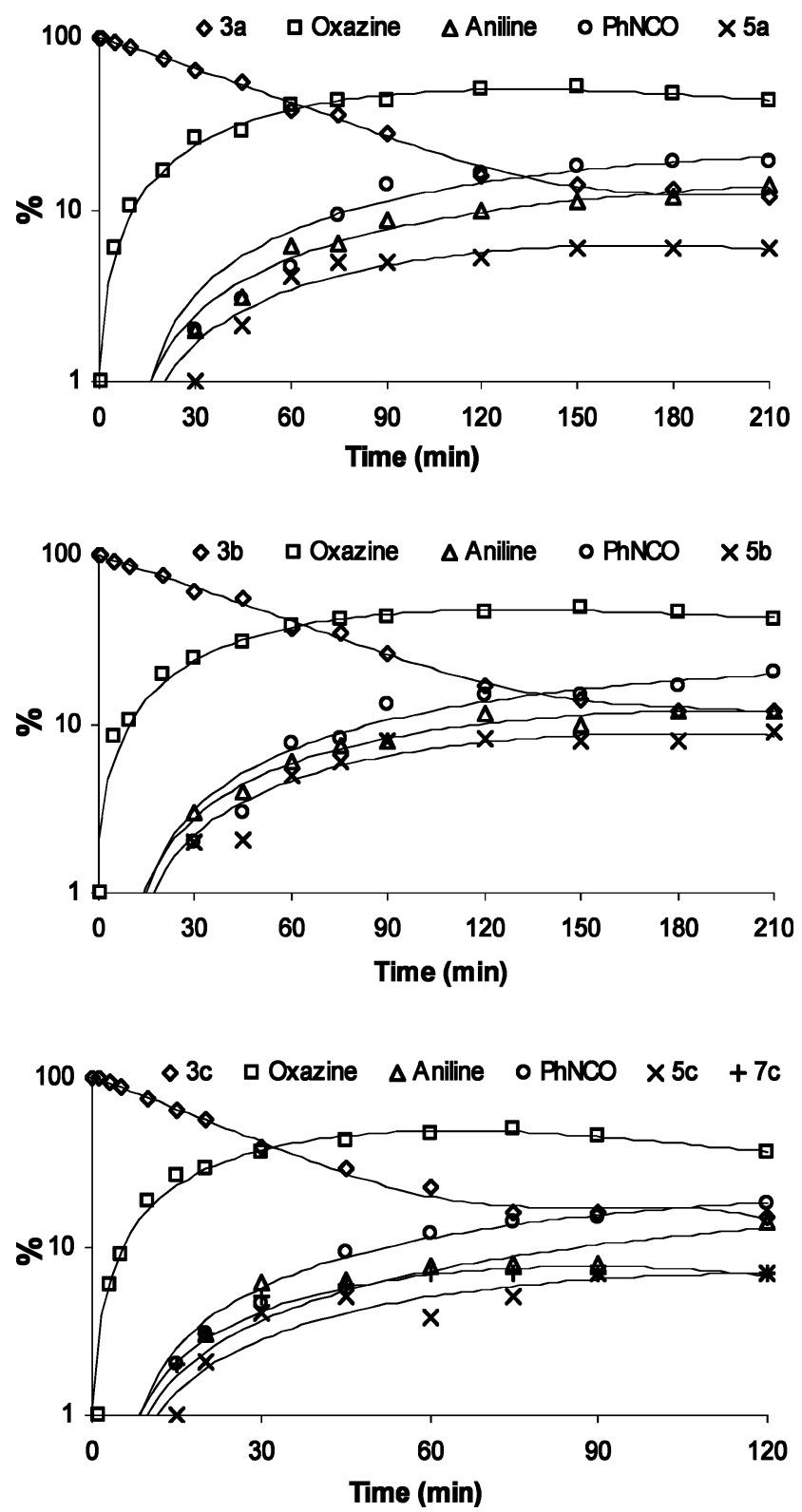

Fig. 5 Time evolution of the amount of 5-allyloxy-tetrazoles $\mathbf{3 a - c}$ and of photoproducts resulting from UV-irradiation $(\lambda=254 \mathrm{~nm})$ in acetonitrile solution $\left(1 \times 10^{-4} \mathrm{~mol} \mathrm{dm}^{-3}\right)$. The amount of reagent before irradiation was assumed to be $100 \%$. The yields of different photoproducts were monitored by gaseous chromatography. Note that the ordinate scale is logarithmic. Note the assignment of geometrical symbols (rhombs-3a-c, squares - oxazine, triangles - aniline, circles-phenylisocyanate, etc.) to particular photoproducts on top of each frame.
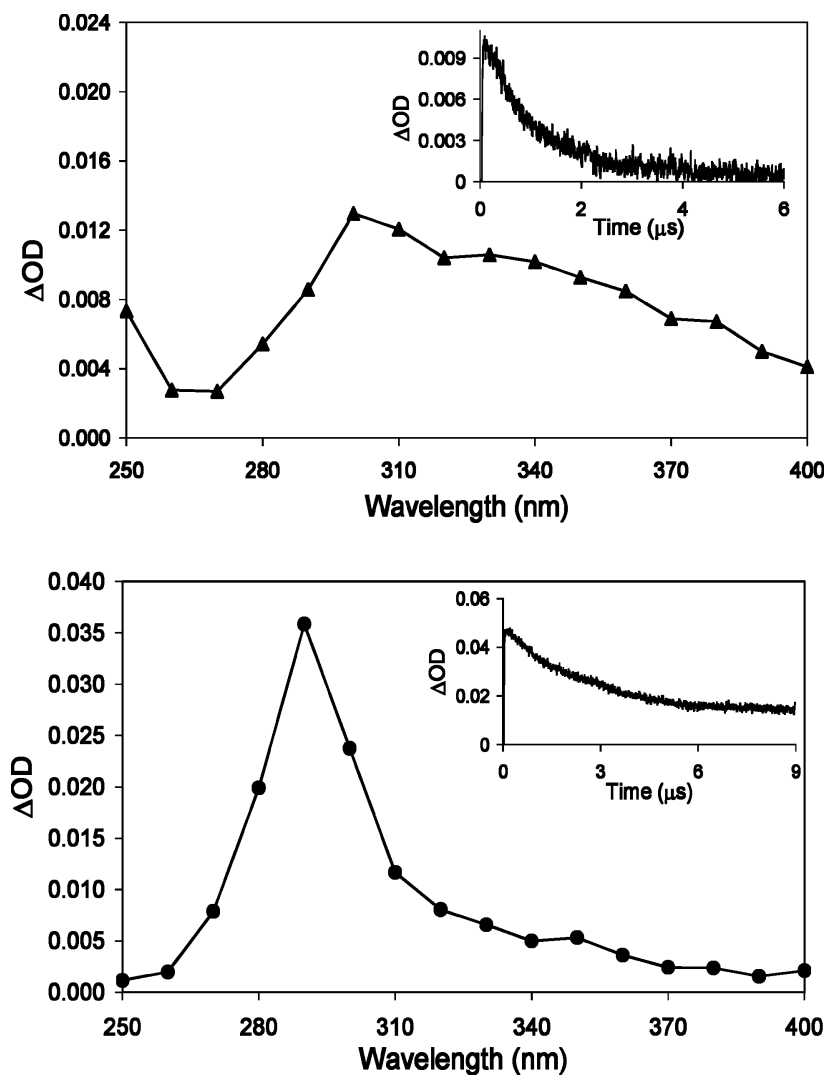

Fig. 6 Absorption spectra observed for the transient species formed upon laser excitation of $\mathbf{3 b}$ (top) and $\mathbf{3 c}$ (bottom) in acetonitrile $(1 \times$ $\left.10^{-4} \mathrm{~mol} \mathrm{dm}^{-3}\right)$, under nitrogen, immediately after the laser $(266 \mathrm{~nm})$ pulse. The inserts show decays, as monitored at $310 \mathrm{~nm}$ (3b, top) and $290 \mathrm{~nm}$ (3c, bottom).

Indeed, the photoinduced loss of nitrogen from tetrazoles 3a-c may involve a cycloelimination leading to a diazirine that reacts further to give the observed oxazines $\mathbf{4 a - c}$, or may occur through a biradical intermediate that subsequently cyclises to give the same compounds $\mathbf{4 a - c}$. Usually, the transition state associated with a concerted mechanism (cleavage of two $\mathrm{N}-\mathrm{N}$ formally single bonds and formation of one new $\mathrm{N}-\mathrm{N}$ formally single bond and the transformation of $\mathrm{N}=\mathrm{N}$ double bond into $\mathrm{N} \equiv \mathrm{N}$ triple bond) has a higher polarity than the initial substrate. Considering the variation in polarity associated with the three solvents used in this work, it appears that the solvent polarity effects are weak or absent during tetrazolone photolysis, contrasting with what could be expected for a concerted process occurring via a polar transition state.

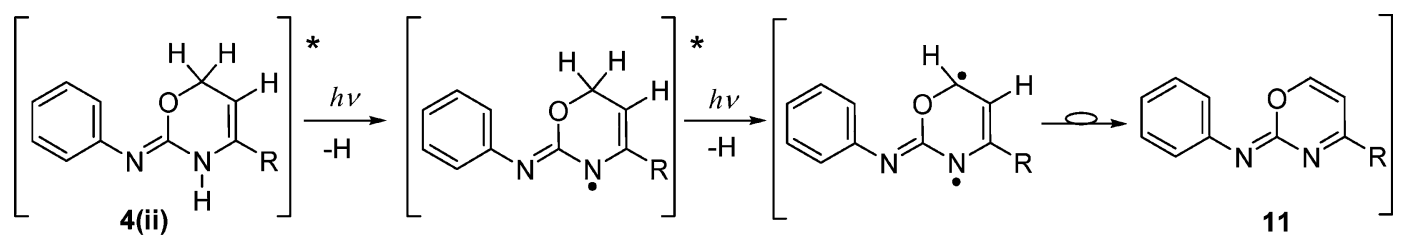

a: $\mathrm{R}=\mathrm{H}, \mathbf{b}: \mathrm{R}=\mathrm{CH}_{3}, \mathbf{c}: \mathrm{R}=\mathrm{Ph}$

Scheme 3 Proposed mechanism for the hydrogen abstraction from oxazines $\mathbf{4 a - c}$ in their $\mathbf{4}$ (ii) tautomer modification. 
It is well known that biradicals are among the most important intermediates in solution-phase organic photochemistry. However, and in agreement with reports in the literature, detection of these intermediates is not easy, and could not be achieved in this work. In some related investigations, such species were detectable only in a limited number of cases. ${ }^{23}$ On the other hand, based on the experimental results obtained, namely on the weak solvent effects, it is our conviction that a radicalar mechanism operates in this case.

Hence, we attribute the observed transients of 5-allyloxytetrazoles 3a-c to the triplet biradicals 3(i) obtained through homolytic cleavage of two $\mathrm{N}-\mathrm{N}$ single bonds, and the observed kinetics to the respective proton transfer reaction 3(i) $\rightarrow$ 3(ii) (see Fig. 2). After conversion of triplet 1,6-biradicals 3(ii) into singlet biradicals via intersystem crossing, these intermediates decay to the ground state yielding final products. Presumably, faster intersystem crossing occurs when the approach of both radical termini becomes easier. In the case of $\mathbf{3 c}$, the triplet excited state lives longer, whereas the proton transfer reaction $\mathbf{3 ( i )} \rightarrow \mathbf{3 ( i i )}$ operates faster, by influence of the phenyl substituent group, and therefore does not limit the overall reaction kinetics, as happens for the substrates $\mathbf{3} \mathbf{a}$ and $\mathbf{3 b}$.

\section{Conclusions}

The results reported in this paper answer several important mechanistic questions concerning the photochemistry of 5-allyloxytetrazoles 3a-c. Photolysis of these compounds in the steady-state has been investigated in methanol, acetonitrile and cyclohexane solutions. Through this study we have shown that the exposure of tetrazoles $\mathbf{3 a}-\mathbf{c}$ to UV light $(\lambda=254 \mathrm{~nm})$ induces a primary photochemical process in which molecular nitrogen is eliminated, producing oxazines $\mathbf{4 a - c}$. In preparative-scale experiments, compounds $\mathbf{4 a}-\mathbf{c}$ were isolated from the reaction medium and fully characterized. DFT(B3LYP)/6-31G(d,p) calculations predict that, in the gaseous phase, oxazines $\mathbf{4 a - c}$ should mostly exist in the tautomeric form where the NH group is the bridge connecting the oxazine and phenyl rings (the lowest-energy structures). The tautomers of $\mathbf{4 a - c}$ with the $\mathrm{NH}$ function included in the oxazine ring are higher in energy, the differences exceeding $7.5 \mathrm{~kJ} \mathrm{~mol}^{-1}$. However, it is expected that, in the polar media, the higherenergy forms of oxazines will undergo additional stabilization with respect to the lowest-energy structures, and the relative population of the minor conformer will increase. In fact, secondary photoproduct analysis supports this interpretation. It is clear from the experiments that the presence of both oxazine tautomers is relevant in solution, increasing the number of secondary photodegradation channels in the three solvents. From these, phenyl vinyl-hydrazines $\mathbf{5 a - c}$, enamines $\mathbf{7 a - c}$, aniline and phenylisocyanate were obtained. The pathway leading to production of phenyl-isocyanate predominates, this resulting from photocleavage of oxazine 4(ii). Kinetic results for the photodegradation of ethers $\mathbf{3 a}-\mathbf{c}$ in different solvents show that the effect of the nature of the solvent on the photoproduct distribution is very weak and the relative yields of photoproducts are maintained in all cases. However, there is a structural effect on the photolysis quantum yields upon introduction of a phenyl on the allylic chain. Mechanistically, primary photoexcitation of 5-allyloxy-tetrazoles should involve formation of a triplet 1,3-biradical with a lifetime of $c a .10^{-6} \mathrm{~s}$, which subsequently isomerizes to form a triplet 1,6biradical. After intersystem crossing, the 1,6-biradical decays to the ground state to form the products.

\section{Experimental section}

\section{Materials}

All chemicals were used as purchased from Aldrich. Solvents for extraction and chromatography were of technical grade. When required, solvents were freshly distilled from appropriate drying agents before use. Compounds $\mathbf{3 a - c}$ were synthesized as described elsewhere. $^{29}$

\section{Equipment and experimental conditions}

Analytical TLC was performed with Merck silica gel $60 \mathrm{~F}_{254}$ plates. Melting points were recorded on a Stuart Scientific SMP3 melting point apparatus and are uncorrected. UV absorption spectra were recorded on a Varian CARY 50 Bio UV-Visible Spectrophotometer. Mass spectra were obtained on a VG 7070E mass spectrometer by electron ionization (EI) at $70 \mathrm{eV} .{ }^{1} \mathrm{H}$ NMR (400 MHz) spectra were obtained on a Bruker AM400 spectrometer using TMS as the internal reference $(\delta=$ $0.0 \mathrm{ppm})$. Elemental analyses were performed on an EA1108Elemental Analyzer (Carlo Erba Instruments). Infrared spectra were obtained as neat oils, or solids in $\mathrm{NaCl}$ on a Bruker FTIRTENSOR 27 spectrometer.

HPLC analyses were performed using an Agilent 1100 Series chromatograph with a 655A-22 UV detector and Shimadzu SPDM6A Photodiode Array. A LiChroCART 125 column (RP-18, $5 \mu \mathrm{m}$, Merck) was used and the runs were performed using a mixture of water and acetonitrile $(40: 60)$ as the eluent.

GC-MS analyses were carried out using a 6890-N Network GC System gas chromatograph with a 5973 inert Mass Selective Detector (E.I. $70 \mathrm{eV}$ ) of Agilent Technologies, using a DB$35 \mathrm{MS}$ capillary column with $30 \mathrm{~m}$ length and $0.25 \mathrm{~mm}$ I.D. (J \& W Scientific, Agilent). The initial temperature of $50{ }^{\circ} \mathrm{C}$ was

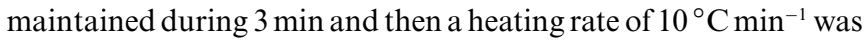
applied, until a final temperature of $250{ }^{\circ} \mathrm{C}$ was reached. Analyses were conducted on irradiated samples and on control solutions, kept in darkness. Controls showed no sign of degradation.

\section{Optical bench irradiation system}

Steady-state photolysis experiments were carried out in acetonitrile, cyclohexane and methanol using $1 \times 1 \mathrm{~cm}$ fused-silica cells (Hellma) on a standard optical bench system. Photolyses were conducted with the cells at a distance of 10 to $40 \mathrm{~cm}$ from the $\mathrm{Hg}$ lamp. Generally, $10^{-4} \mathrm{~mol} \mathrm{dm}^{-3}$ solutions of substrates were used when the analysis was carried out by UV-Visible absorption spectrophotometry. More concentrated solutions $\left(10^{-2} \mathrm{~mol} \mathrm{dm}^{-3}\right)$ were irradiated under the same conditions for product identification using GC-MS and HPLC. The $254 \mathrm{~nm}$ UV radiation was performed using a $16 \mathrm{~W}$ low-pressure mercury lamp (Applied Photophysics). A suitable interference filter was used to isolate the $254 \mathrm{~nm}$ line of the $\mathrm{Hg}$ lamp. Photolysis quantum yields were measured using ferrioxalate actinometer. ${ }^{32-34}$ 


\section{Laser flash-photolysis}

Flash photolysis experiments were carried out on an Applied Photophysics LKS.60 laser-flash-photolysis spectrometer, with a Spectra-Physics Quanta-Ray GCR-130 Nd/YAG laser (fourth harmonic, $266 \mathrm{~nm}$ ) for excitation and a Hewlett-Packard Infinium Oscilloscope for transient decay capture. Sample solutions were pumped through a quartz cell at a $0.8 \mathrm{~mL} \mathrm{~min}^{-1}$ flow rate (SSI chromatographic pump).

\section{Computational methods}

The equilibrium geometries for compounds $4 \mathbf{a}-\mathbf{c}, \mathbf{5 a}-\mathbf{c}, \mathbf{6}$, 7a-c, 8, 9, 10 and 11a-c were fully optimized at the DFT level of theory with the standard $6-31 \mathrm{G}(\mathrm{d}, \mathrm{p})$ basis set, using the Gaussian 03 program. ${ }^{35}$ DFT calculations were carried out with the B3LYP three-parameter density functional, which includes Becke's gradient exchange correction ${ }^{36}$ and the Lee, Yang and Parr correlation functional. ${ }^{37}$ No symmetry restrictions were imposed on the initial structures. Geometries, energies and Cartesian coordinates for the most stable conformers of molecules studied are included as ESI (pages S4-S26).†

\section{General procedure for the preparation of compounds $4 a-c$ (preparative scale irradiations)}

Irradiations at $\lambda=254 \mathrm{~nm}$ were carried out using a $10 \mathrm{~mL}$ cylindrical quartz cell with a $50 \mathrm{~mm}$ light path (Hellma). Solutions of ethers $3 \mathbf{a}-\mathbf{c}$ ( $50 \mathrm{mg}$ in $10 \mathrm{~mL}$ of acetonitrile) were irradiated with continuous stirring, with the cell at a distance of $10 \mathrm{~cm}$ from the $\mathrm{Hg}$ lamp. The sample irradiation continued until detection of a secondary photoproduct, corresponding to the substrate conversion of about $30 \%$, as monitored by HPLC analysis. At this point the solutions were removed and evaporated to concentrate the photoproducts. The photoproducts $\mathbf{4 a}-\mathbf{c}$ were isolated from the crude by column chromatography on silica gel, using a mixture of hexane and ethyl acetate as eluent. 1,3-Oxazines 4a-c were obtained as light-yellow oils.

$\boldsymbol{N}$-Phenyl-6H-1,3-oxazin-2-amine (4a). Ether 3a was irradiated during $10 \mathrm{~h}$. The crude oil was chromatographed on silica gel (hexane-AcOEt $10: 1$ ), to give $15 \mathrm{mg} \mathrm{(34 \% )} \mathrm{of} \mathbf{4 a}$ as a yellow oil. IR (NaCl disks), $v_{\max }: 3270(\mathrm{~N}-\mathrm{H}), 1672,1642,1595,1560,1498$, 1448, 1228, 1073, 1021, 992 and $759 \mathrm{~cm}^{-1} ;{ }^{1} \mathrm{H}$ NMR $(400 \mathrm{MHz}$, $\left.\mathrm{CDCl}_{3}\right): \delta 4.22(1 \mathrm{H}, \mathrm{s}, \mathrm{N}-\mathrm{H}), 5.06-5.10\left(2 \mathrm{H}, \mathrm{d},-\mathrm{CH}_{2}-\right), 5.33-5.38$ $(1 \mathrm{H}, \mathrm{d},=\mathrm{CH}-\mathrm{N}), 6.05-6.08(1 \mathrm{H}, \mathrm{m}), 7.36-7.45(1 \mathrm{H}, \mathrm{d}), 7.46-7.52$ (2H, t), 7.64-7.69 (2H, d) ppm; MS (EI), $m / z 175[\mathrm{M}+\mathrm{H}]^{+}$; Acc. Mass (CI): found $=175.1312$, calcd for $\mathrm{C}_{10} \mathrm{H}_{11} \mathrm{~N}_{2} \mathrm{O}: 175.1344$.

4-Methyl- $\boldsymbol{N}$-phenyl-6H-1,3-oxazin-2-amine (4b). Ether 3b was irradiated during $10 \mathrm{~h}$. The crude oil was chromatographed on silica gel (hexane-AcOEt $10: 1)$, to give $13 \mathrm{mg}(30 \%)$ of $\mathbf{4 b}$ as a yellow oil. IR ( NaCl disks), $v_{\max }$ : $3264(\mathrm{~N}-\mathrm{H}), 2929,1673,1638$, 1595, 1559, 1498, 1448, 1368 and $757 \mathrm{~cm}^{-1} ;{ }^{1} \mathrm{H}$ NMR $(400 \mathrm{MHz}$, $\left.\mathrm{CDCl}_{3}\right): \delta 0.92\left(3 \mathrm{H}, \mathrm{s},-\mathrm{CH}_{3}\right), 4.20-4.24\left(2 \mathrm{H}, \mathrm{t},-\mathrm{CH}_{2}-\right), 5.02-5.08$ $(1 \mathrm{H}, \mathrm{t},=\mathrm{CH}), 5.34(1 \mathrm{H}, \mathrm{s}, \mathrm{N}-\mathrm{H}), 7.45-7.54(3 \mathrm{H}, \mathrm{m}), 7.69-7.75$ (2H, d) ppm; MS (EI), $m / z 189[\mathrm{M}+\mathrm{H}]^{+}$; Acc. Mass (CI): found = 189.2161, calcd for $\mathrm{C}_{11} \mathrm{H}_{13} \mathrm{~N}_{2} \mathrm{O}: 189.2171$.

$\boldsymbol{N}, 4$-Diphenyl-6H-1,3-oxazin-2-amine (4c). Ether 3c was irradiated during $6 \mathrm{~h}$. The crude oil was chromatographed on silica gel (hexane-AcOEt $6: 1)$, to give $15 \mathrm{mg}(33 \%)$ of $\mathbf{4 c}$ as a yellow oil. IR ( $\mathrm{NaCl}$ disks), $v_{\max }: 3255(\mathrm{~N}-\mathrm{H}), 1678,1597,1543,1498,1444$, 1314, 1250, 1223 and $752 \mathrm{~cm}^{-1} ;{ }^{1} \mathrm{H}$ NMR (400 MHz, $\mathrm{CDCl}_{3}$ ): $\delta$ 4.79-4.81 (2H, d, $\left.-\mathrm{CH}_{2}-\right), 5.42(1 \mathrm{H}, \mathrm{s}, \mathrm{N}-\mathrm{H}), 6.72-6.79(1 \mathrm{H}$, $\mathrm{t},=\mathrm{CH}), 7.28-7.33(3 \mathrm{H}, \mathrm{m}), 7.43-7.48(4 \mathrm{H}, \mathrm{m}), 7.55-7.60(3 \mathrm{H}$, m) ppm; MS (EI), $m / z 251[\mathrm{M}+\mathrm{H}]^{+}$. Acc. Mass (CI): found = 251.2312, calcd for $\mathrm{C}_{16} \mathrm{H}_{15} \mathrm{~N}_{2} \mathrm{O}: 251.2312$.

\section{Acknowledgements}

The authors are grateful to Fundação para a Ciência e a Tecnologia (FCT) and FEDER for financial support, through projects POCI/QUI/59019/2004, POCI/QUI/58937/2004 and PTDC/QUI/67674/2006 and grant SFRH/BD/17945/2004 (L.M.T.F).

\section{References}

1 G. Sandmann, C. Schneider and P. Boger, Z. Naturforsch., C, 1996, 51, 534.

2 S. C. S. H. Singh, A. Chawla, V. Kapoor, D. Paul and R. Malhotra, Prog. Med. Chem., 1980, 17, 151.

3 J. H. Toney, P. M. D. Fitzgerald, N. Grover-Sharma, S. H. Olson, W. J. May, J. G. Sundelof, D. E. Vanderwall, K. A. Cleary, S. K. Grant, J. K. Wu, J. W. Kozarich, D. L. Pompliano and G. G. Hammond, Chem. Biol., 1998, 5, 185.

4 R. J. Herr, Bioorg. Med. Chem., 2002, 10, 3379.

5 T. Mavromoustakos, A. Kolocouris, M. Zervou, P. Roumelioti, J. Matsoukas and R. Weisemann, J. Med. Chem., 1999, 42, 1714.

6 Y. Hashimoto, R. Ohashi, Y. Kurosawa, K. Minami, H. Kaji, K. Hayashida, H. Narita and S. Murata, J. Cardiovasc. Pharmacol., 1998, 31, 568 .

7 A. Desarro, D. Ammendola, M. Zappala, S. Grasso and G. B. Desarro, Antimicrob. Agents Chemother, 1995, 39, 232.

8 Y. Tamura, F. Watanabe, T. Nakatani, K. Yasui, M. Fuji, T. Komurasaki, H. Tsuzuki, R. Maekawa, T. Yoshioka, K. Kawada, K. Sugita and M. Ohtani, J. Med. Chem., 1998, 41, 640.

9 A. D. Abell and G. J. Foulds, J. Chem. Soc., Perkin Trans. 1, 1997, 2475.

10 G. I. Koldobskii, V. A. Ostrovskii and V. S. Poplavskii, Khim. Geterotsikl. Soedin., 1981, 1299.

11 C. Zhao-Xu and X. Heming, Int. J. Quantum Chem., 2000, 79, 350.

12 Y. B. Chae, K. S. Chang and S. S. Kim, Daehan Hwahak Hwoejee, 1967, 11, 85.

13 G. Maier, J. Eckwert, A. Bothur, H. P. Reisenauer and C. Schmidt, Liebigs Ann., 1996, 1041.

14 A. Awadallah, K. Kowski and P. Rademacher, J. Heterocycl. Chem., 1997, 34, 113.

15 L. M. T. Frija, I. D. Reva, A. Gómez-Zavaglia, M. L. S. Cristiano and R. Fausto, Photochem. Photobiol. Sci., 2007, 6, 1170.

16 L. M. T. Frija, I. D. Reva, A. Gómez-Zavaglia, M. L. S. Cristiano and R. Fausto, J. Phys. Chem. A, 2007, 111, 2879.

17 A. Gómez-Zavaglia, I. D. Reva, L. Frija, M. L. Cristiano and R. Fausto, J. Photochem. Photobiol., A, 2006, 180, 175.

18 A. Gómez-Zavaglia, I. D. Reva, L. Frija, M. L. Cristiano and R. Fausto, J. Photochem. Photobiol., A, 2006, 179, 243.

19 A. Gómez-Zavaglia, I. D. Reva, L. Frija, M. L. Cristiano and R. Fausto, J. Mol. Struct., 2006, 786, 182.

20 A. Gómez-Zavaglia, I. D. Reva, L. Frija, M. L. Cristiano and R. Fausto, J. Phys. Chem. A, 2005, 109, 7967.

21 L. M. T. Frija, I. V. Khmelinskii and M. L. S. Cristiano, J. Org. Chem., 2006, 71, 3583 .

22 L. M. T. Frija, I. V. Khmelinskii and M. L. S. Cristiano, Tetrahedron Lett., 2005, 46, 6757.

23 I. R. Dunkin, C. J. Shields and H. Quast, Tetrahedron, 1989, 45, 259.

24 H. Quast, Heterocycles, 1980, 14, 1677.

25 H. Quast and L. Bieber, Angew. Chem., Int. Ed. Engl., 1975, 14, 428.

26 H. Quast and L. Bieber, Chem. Ber./Recl., 1981, 114, 3253.

27 H. Quast, A. Fuss and U. Nahr, Chem. Ber./Recl., 1985, 118, 2164. 
28 H. Quast and U. Nahr, Chem. Ber./Recl., 1985, 118, 526.

29 M. L. S. Cristiano and R. A. W. Johnstone, J. Chem. Soc., Perkin Trans. 2, 1997, 489.

30 S. De Feyter, E. W.-G. Diau and A. H. Zewail, Phys. Chem. Chem. Phys., 2000, 2, 877.

31 S. Zimbros and Y. Haas, Phys. Chem. Chem. Phys., 2002, 4, 34.

32 C. A. Parker, Proc. R. Soc. London, Ser. A, 1953, 220, 104.

33 C. G. Hatchard and C. A. Parker, Proc. R. Soc. London, Ser. A, 1956, $235,518$.

34 J. G. Calvert and J. N. J. Pitts, Photochemistry, John Wiley and Sons, New York, 1967.

35 M. J. Frisch, G. W. Trucks, H. B. Schlegel, G. E. Scuseria, M. A. Robb, J. R. Cheeseman, J. A. Montgomery, Jr., T. Vreven, K. N. Kudin, J. C. Burant, J. M. Millam, S. S. Iyengar, J. Tomasi, V. Barone, B. Mennucci, M. Cossi, G. Scalmani, N. Rega, G. A. Petersson, H. Nakatsuji, M.
Hada, M. Ehara, K. Toyota, R. Fukuda, J. Hasegawa, M. Ishida, T. Nakajima, Y. Honda, O. Kitao, H. Nakai, M. Klene, X. Li, J. E. Knox, H. P. Hratchian, J. B. Cross, V. Bakken, C. Adamo, J. Jaramillo, R. Gomperts, R. E. Stratmann, O. Yazyev, A. J. Austin, R. Cammi, C. Pomelli, J. Ochterski, P. Y. Ayala, K. Morokuma, G. A. Voth, P. Salvador, J. J. Dannenberg, V. G. Zakrzewski, S. Dapprich, A. D. Daniels, M. C. Strain, O. Farkas, D. K. Malick, A. D. Rabuck, K. Raghavachari, J. B. Foresman, J. V. Ortiz, Q. Cui, A. G. Baboul, S. Clifford, J. Cioslowski, B. B. Stefanov, G. Liu, A. Liashenko, P. Piskorz, I. Komaromi, R. L. Martin, D. J. Fox, T. Keith, M. A. Al-Laham, C. Y. Peng, A. Nanayakkara, M. Challacombe, P. M. W. Gill, B. G. Johnson, W. Chen, M. W. Wong, C. Gonzalez and J. A. Pople, GAUSSIAN 03 (Revision C.02), Gaussian, Inc., Wallingford, CT, 2004.

36 A. D. Becke, Phys. Rev. A, 1988, 38, 3098.

37 C. T. Lee, W. T. Yang and R. G. Parr, Phys. Rev. B, 1988, 37, 785. 